\title{
Enhance The Study Of Accounting With Those Negative Headlines
}

Judith A. Laux, (Email: jlaux@coloradocollege.edu), Colorado College

\begin{abstract}
The following treatise offers the argument that Enron and like scandals represent an opportunity to serve the profession by exciting our students, dispelling the stereotypes, elevating theoretical objectives above statistical sampling, catapulting accountants into a more symbiotic relationship with managers, expanding the career paths of accountants, and providing a springboard for improved teaching.
\end{abstract}

R ecent scandalous headlines in the accounting arena have placed those who teach accounting and related subjects squarely in the sights of other academicians and business practitioners who demand an explanation for fraudulent reporting. While we know the failure to generate financial reports that reflect economic reality lies in the hands of a multitude of players, we must see beyond the furor and recognize that these headlines offer an opportunity to enhance what we do in the classroom as well as in our businesses. This paper offers the argument that recent accounting scandals can enhance the study of accounting in a multitude of ways. The scandals can attract students to the study of accounting; help convey the reality that accounting is more conceptual than mathematical; open up broader employment opportunities for those who study accounting, and provide a basis for discussing virtually all the major issues covered at the intermediate accounting level.

What better way to attract students to the study of accounting than to offer up scandalous cases, ones that have at their very heart subversion of accounting objectives? Students read the Wall Street Journal, and the headlines walk into every class. "Murky Waters: A Primer on Enron Partnerships [1/21/02,C1]" "Deciphering the Black Box: Many Accounting Practices, Not Just Enron's, Are Hard to Penetrate [1/23/02,C1]" "SEC Widens Xerox Civic Probe to Ex-Executives and to KPMG [4/10/02,A1]" "Andersen's Fall From Grace Is a Tale of Greed and Miscue [6/7/02,A1]" It is as if we've been given a marketing tool to make us stand out from the competition! Studies have shown that students learn material better (and enjoy doing so much more) when theoretical constructs are connected to the real world. It is this connection that makes the material more alive and exciting--something we know the field of accounting can use. Forensic accounting also helps dispel the accounting stereotype--one of the oft-mentioned barriers to the field.

And what about the stereotype? Admittedly, any accounting instructor worth his or her salt can dismiss the "bean counter" myth in the introductory course. Most students emerge from the course with a better understanding of business and of how accounting information is used, but how many students never take the course because they hold the myth to be true? Now, suddenly, we have the Enrons, Tycos, and WorldComs to persuade these reluctant students that accounting is a course they should take to participate fully in what should be an animated discussion for years to come. It becomes much easier to convince them that accounting goes (and always has gone) beyond number crunching.

As a matter of fact, one of the emerging lessons from recent scandals is that perhaps accountants spend too much time confirming numbers and too little time investigating the underlying economic realities that those numbers allegedly reflect. They are more comfortable performing the statistical sampling required in a good audit than wading through the disclosures relegated to footnotes. What this indicates is that we do a much better job of teaching the systematic steps than the theoretical objectives (such as "economic substance over legal form" and

$\overline{\text { Readers with comments }}$ or questions are encouraged to contact the author via email. 
"predictive ability"). In our recruiting, we must find students who like the idea of combining an accounting background with fields such as economics, finance, organizational behavior, and business policy and strategy. Equipped with these tools, they may become better accountants (or better managers, if they choose that path instead). As Baruch Lev, professor of accounting and finance at Stern School of Business, points out:

\section{...[W] hile there are highly qualified people working in accounting firms, it's questionable whether much of the rank and file is up to the task of auditing enterprises of $21^{\text {st }}$ century complexity. It would have taken an experienced Ph.D. to really grasp Enron's energy and broadband derivatives or to tease apart the structure and implications of "special purpose entities." ["Too Gray for Its Own Good," Wall Street Journal, 1/22/02, A20]}

Furthermore, he recommends revamping the audit report to "provide an open-ended opinion on a series of fundamental issues..."This type of reflective statement, wherein theoretical objectives would be connected to the numbers, will require both the ability to comprehend accounting theory and to convey it articulately to those who will be guided by its essence.

In the intermediate accounting course, we must inform students that the accountants of the future may well play a more active role in managerial decision making. Their expertise in making the numbers reflect the underlying economic reality will be indispensable to managers who must prove to their stockholders that running a sound business is more important than making quarterly earnings estimates. Fewer accounting "games" should result, and managers could well place a premium on accountants who are willing to resist such pressures. In fact, the audit committees of the future (another potential career possibility) may face different qualifications for membership, including "significant accounting, auditing, finance, or legal expertise, and general management responsibility without direct involvement in one of those areas should not be sufficient." [Beresford and Thomas, "After Enron: Let's Not Throw Out the Baby," CPA Journal, July 2002].

Furthermore, the scandals have demanded a separation of the audit and consulting functions, and although neither auditing nor consulting will go away, they will be subject to a more powerful microscope. To attract the brightest candidates to these fields, salaries may well increase in the near future, always a potent recruiting device. In addition, Boone and Coe ["The 150-Hour Requirement..." Issues in Accounting Education, Vol. 17, August 2002, 253-68.] investigate the recent decrease in the supply of accounting undergraduates, noting that the 150-hour requirement is not solely responsible and citing noncompetitive compensation and unattractive working conditions as significant associate causes. Improved perceived working conditions could be one potential outcome as consulting and auditing are separated and the two paths allow students to choose their "first love." Again, this can only help the recruiting effort. We also hear the call for the next generation of "forensic accountants," a potentially lucrative profession. Finally, with the new regulations, "Congress [has] created more work for [directors, CEOs, and accountants], not to mention a raft of new business for consultants, lawyers, and many others" [Wall Street Journal, $7 / 16 / 02, \mathrm{~B} 1]$, so putting that accounting background to good use should be easier in the future.

Finally, and most compelling, the recent "black eyes" for the profession provide a great teaching device. In accounting, we have the opportunity to walk through the balance sheet and income statement and point out the ethical challenges, the conflicts of interest, and the earnings management problem in a more resolute but constructive way. In intermediate accounting, we can now discuss with more animation such topics as accounting for derivatives and stock options, revenue acceleration and expense recognition, income smoothing, off balance sheet financing, and asset valuation. The scandals are ripe with examples for finance, investments, and organizational behavior classes, as well as business ethics. We would be remiss if we did not open our eyes to the possibility that students could learn to be better accountants, financial managers, or investment advisors by virtue of exposing them to some of the details of these cases.

Though many thought the Enron scandal was the beginning of the end, perhaps it actually represents an opportunity. The case has been made for these negative headlines to serve the profession by exciting our students, dispelling the stereotypes, elevating theoretical objectives above statistical sampling, catapulting accountants into a more symbiotic relationship with managers, expanding the career paths of accountants, and providing a springboard for improved teaching. 